Altai State University

www.asu.ru

ISSN 2412-1908

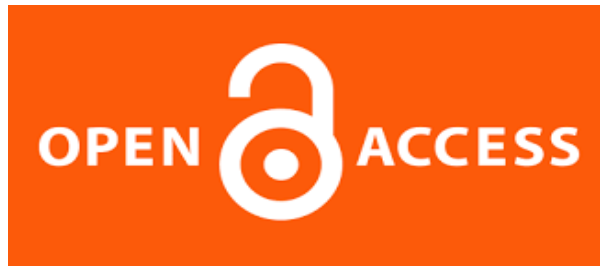

Acta Biologica Sibirica, 2018, 4(3), 69-74

\title{
Impact of mining on macroinvertebrate species richness in mountain streams
}

\author{
L.V. Yanygina ${ }^{1,2}$, A.A. Yevseyeva ${ }^{3}$ \\ ${ }^{1}$ Institute for Water and Environmental Problems SB RAS, Barnaul, Russia \\ ${ }^{2}$ Altai State University, Barnaul, Russia, E-mail: zoo@iwep.ru \\ ${ }^{3}$ Altai Branch of Kazakh Scientific-Research Institute of Fisheries, Ust-Kamenogorsk, Republic of Kazakhstan, E- \\ mail: annaeco@mail.ru
}

\begin{abstract}
Mining is a major source of environmental degradation in mountains. To assess the negative impact of mining on aquatic ecosystems, the bottom communities of a small mountain Breksa river (South-Western Altai), which receives drainage water from the mining enterprises, were investigated. Macroinvertebrate samples were taken monthly from April to October 2005-2010 at the background site and the impact zone of Breksa river. A significant decrease in macroinvertebrate species richness was found in the impact zone as compared to the background site. Each sample upstream from the impact zone contained $18 \pm 1.5$ macroinvertebrate species, while downstream - only $6.5 \pm 0.6$ species. The species richness correlated negatively with the content of suspended substances in water $(r=-0.32)$ and the concentration of heavy metals ( $r=-0.69$ ). Changes in the composition of the most frequent species caused by pollution are revealed. The most sensitive and resistant to pollution macroinvertebrates are presented. The most sensitive to pollution are mayflies Epeorus pellucidus, Neoleptophlebia chocolata, caddisflies Hydropsyche newae, Brachycentrus americanus, Dicosmoecus palatus, Glossosoma altaicum, and crustaceans Gammarus korbuensis. The most resistant are chironomids larvae. The data obtained prove the necessity of regional modifications of widespread European methods of water quality bioindication.
\end{abstract}

Key words: macroinvertebrates; heavy metals; mining; species richness.

\section{Влияние горнодобывающей деятельности на видовое богатство макробеспозвоночных горных водотоков}

\author{
Л.В. Яныгина ${ }^{1,2}$, А.А. Евсеева ${ }^{3}$ \\ ${ }^{1}$ Институт водных и экологических проблем СО РАН, Барнаул, Россия \\ ${ }^{2}$ Алтайский государственный университет, Барнаул, Россия, E-mail: zоo@@iwep.ru \\ ${ }^{3}$ Алтайский филиал ТОО «Казахский научно-исследовательский институт рыбного хозяйства», Усть- \\ Каменогорск, Казахстан, E-mail: annaeco@mail.ru
}

Горнодобывающая деятельность является одним из основных источников деградации окружающей среды горных территорий. Для оценки факторов негативного влияния горнодобывающей деятельности на водные экосистемы были исследованы донные сообщества малой горной реки Брексы (Юго-Западный Алтай), принимающей дренажные воды предприятий горнодобывающего комплекса. Сборы донных макробеспозвоночных проводили ежемесячно с апреля по октябрь 2005-2010 г. на фоновом участке и в импактной зоне р. Брекса. Отмечено существенное снижение видового богатства макробеспозвоночных в импактной зоне по сравнению с фоновым

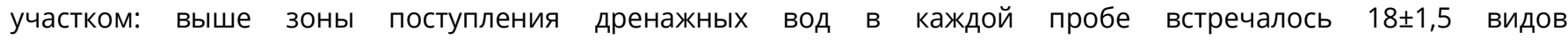




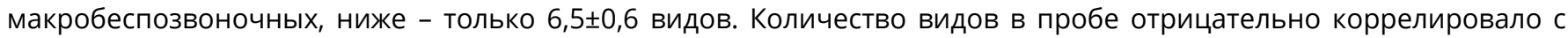
содержанием взвешенных веществ в воде ( $r=-0.32)$, а также с концентрацией тяжелых металлов ( $r=-0.69)$. Выявлены изменения состава наиболее часто встречающихся видов под влиянием загрязнения. Впервые для водотока представлен список наиболее чувствительных и устойчивых к загрязнению видов макробеспозвоночных. Наиболее чувствительны к загрязнению поденки Epeorus pellucidus, Neoleptophlebia chocolata, ручейники Ceratopsyche newae, Brachycentrus americanus, Dicosmoecus palatus, Glossosoma altaicum, a также ракообразные Gammarus korbuensis. Наиболее устойчивы к загрязнению личинки хирономид. Полученные данные обосновывают необходимость проведения региональных модификаций широкораспространенных европейских методов биоиндикации качества воды.

Key words: макробеспозвоночные; тяжелые металлы; горнодобывающая деятельность; видовое богатство.

\section{Введение}

Биологическое разнообразие - главный природный ресурс, поддерживающий основные функции биосферы и обеспечивающий ее регенерацию, устойчивость к негативным природным и антропогенным воздействиям (Tishkov, 2006). Горные экосистемы характеризуются более высокими, по сравнению с равнинными территориями, показателями биоразнообразия, что, вероятно, связано с большим разнообразием природных условия в горах, мозаичностью местообитаний (Bioraznoobrazie ..., 2006).

Алтае-Саянская горная страна представляет особый интерес в изучении и сохранении биоразноообразия как один из наиболее богатых в таксономическом отношении регионов мира. Высокая значимость Алтае-Саянского экорегиона подчеркивается его включением Всемирным фондом дикой природы в список 200 территорий мира, в которых сосредоточено более 90\% биоразнообразия планеты. В число основных угроз биоразнообразию, в том числе и горных территорий, входят загрязнение окружающей среды, изменение и разрушение местообитаний. Алтае-Саянская горная страна в целом относится к территориям, наименее измененным в результате хозяйственной деятельности человека. Однако отдельные ее участки испытывают интенсивные антропогенные модификации, что несет угрозу сохранению биоразнообразию. Юго-западный Алтай (Рудный Алтай) относится к старейшим горнорудным районам России, на его территории ведется активная добыча медных, свинцовых руд, золота и серебра. Деятельность горнодобывающих предприятий является одним из наиболее значимых факторов трансформации как наземных, так и водных экосистем горных территорий. В результате такого воздействия возникают техногенные формы рельефа, трансформируется водный сток рек региона, ухудшается качество поверхностных вод, в том числе, и в результате поступления в водные объекты высокотоксичных для живых организмов соединений тяжелых металлов. Для оценки возможных изменений, предотвращения негативных последствий и сохранения биоразнообразия региона необходимо проведение исследований по оценке и выявлению особенностей динамики разнообразия в том числе и на участках, подверженных интенсивной антропогенной трансформации.

Цель данной работы - изучение видового богатства макробеспозвоночных р. Брекса (Юго-Западный Алтай) и оценка особенностей его трансформации в зоне деятельности горнодобывающих предприятий.

\section{Материал и методы}

Материал для данный работы собран в р. Брекса, малой реке Юго-Западного Алтая, притоке р. Ульба (бассейн р. Иртыш). Река протекает в Восточно-Казахстанской области Казахстана (50¹9'34' 'N, 8332'43' 'Е). Длина р. Брекса 22,8 км, площадь водосбора 150 км². Пробы зообентоса р. Брекса отбирали на двух станциях: 6,8 км выше г. Риддера (В1, фоновый участок) и в черте г. Риддера ниже сброса дренажных вод АО «Казцинк» (В2, импактная зона) ежемесячно с апреля по октябрь 2005-2010 гг. (рис. 1).

Пробы зообентоса отбирали гидробиологическим скребком с режущей кромкой шириной 18 см. На каждом участке пробы собирали с поверхности грунта полосой в 1 м пятикратно, площадь облова при этом составляла 0,9

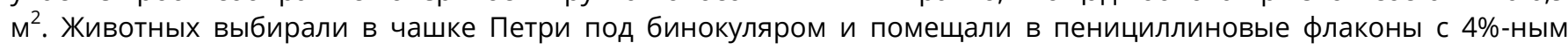
раствором формалина. В лаборатории беспозвоночных определяли до вида (кроме хирономид, идентифицированных до семейства, и водных клещей, идентифицированных до надсемейства) и взвешивали на аналитических электронных весах ALJ 220-4 фирмы «Kern» (Германия) с дискретностью отсчета 0,1 мг.

Одновременно с бентосными сборами отобраны пробы воды для гидрохимического анализа, который выполнен сотрудниками группы мониторинга состояния поверхностных вод Комплексной лаборатории ВосточноКазахстанского центра гидрометеорологии. Вода реки гидрокарбонатного типа, слабощелочная (рН 8,1), малой минерализации (42-168 мг/л). В нижнем течении река принимает дренажные воды «Казцинка», расположенного в промышленной зоне г. Риддер. Ниже зоны поступления дренажных вод качество воды ухудшается в разные годы до V-VII класса (грязные-чрезвычайно грязные). 


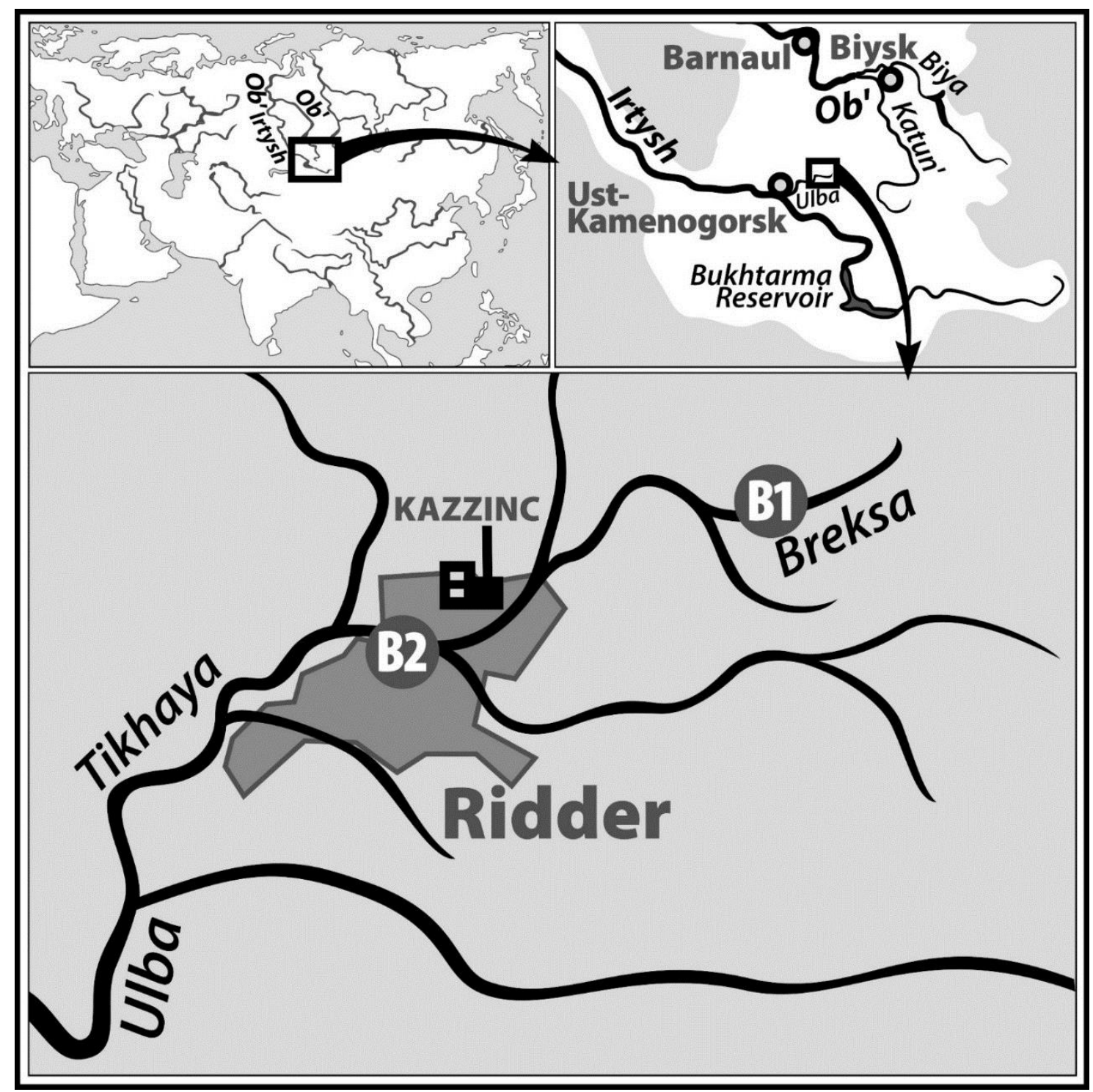

Рис. 1. Схема расположения точек отбора проб.

Частоту встречаемости макробеспозвоночных рассчитывали как отношение числа проб, в которых вид отмечен, к общему количеству проб. По частоте встречаемости все виды разделены на константные встречаемость более 50\%, второстепенные - 25-50\%, случайные - менее 25\% (Bakanov, 2005).

Видовое богатство макробеспозвоночных оценивали по числу обнаруженных видов.

Статистический анализ данных проводился с использованием программы «Statistica 6.0». Для анализа взаимосвязи количественных признаков рассчитаны ранговые корреляции по Спирмену. При сравнении выборок использовали непараметрический метод Манна-Уитни. Нулевую гипотезу об отсутствии различий между выборками отвергали при $p<0,05$.

\section{Результаты и обсуждение}

Донные сообщества фоновых участков р. Брекса характеризовались относительно высоким видовым богатством:

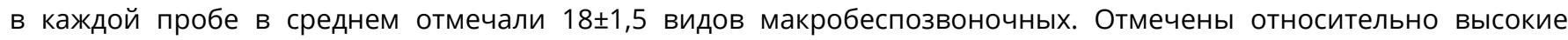
коэффициенты внутригодовой вариации видового богатства макробеспозвоночных (до 52\%) при невысокой (8\%) межгодовой изменчивости (табл. 1). Высокая внутригодовая вариабельность видового богатства связана как со значительной сезонной изменчивостью гидрологического режима рек, так и с особенностью жизненных циклов амфибиотических насекомых, составляющих основу донного населения реки. Схожие тенденции были отмечены и для рек Юго-Восточного Алтая (Yanygina, 2017), для которых было показано снижение видового богатства, численности и биомассы макробеспозвоночных в периоды прохождения пика половодья на реках и массового вылета доминирующих видов амфибиотических насекомых. 
Yanygina, L.V., Yevseyeva, A.A. Impact of mining on macroinvertebrate species.... Acta Biologica Sibirica, 2018, 4(3), 69-74

Таблица 1. Видовое богатство макробеспозвоночных р. Брекса на фоновом участке (Б1) и в импактной зоне (Б2)

\begin{tabular}{lllllllllll}
\hline Год & & апрель & май & июнь & июль & август & сентябрь & октябрь & $\mathrm{M} \pm \mathrm{m}$ & $\mathrm{V}$ \\
\hline \multirow{2}{*}{2005} & Б1 & 6 & 10 & 18 & 6 & 13 & 13 & 12 & $11,1 \pm 1,6$ & 38,2 \\
& Б2 & 1 & 5 & 6 & 6 & 8 & 4 & 5 & $5,0 \pm 0,8$ & 43,2 \\
2006 & Б1 & 4 & 19 & 20 & 21 & 22 & 7 & 9 & $14,6 \pm 2,9$ & 52,1 \\
& Б2 & 3 & 3 & 4 & 7 & 9 & 3 & 3 & $4,6 \pm 0,9$ & 53,4 \\
2008 & Б1 & 22 & 25 & 22 & 21 & 23 & 24 & 17 & $22,0 \pm 1,0$ & 11,7 \\
& Б2 & 5 & 6 & 12 & 7 & 11 & 9 & 7 & $8,1 \pm 1.0$ & 32,1 \\
2009 & Б1 & 19 & 22 & 23 & 24 & 21 & 29 & 24 & $23,1 \pm 1,2$ & 13,5 \\
& Б2 & 3 & 8 & 3 & 9 & 12 & 12 & 4 & $7,3 \pm 1,5$ & 54,7 \\
2010 & Б1 & 20 & 18 & 23 & 24 & 19 & 22 & 25 & $21,6 \pm 1,0$ & 12,2 \\
& Б2 & 3 & 6 & 7 & 8 & 8 & 7 & 6 & $6,4 \pm 0,6$ & 26,7 \\
\hline
\end{tabular}

Примечание: М - среднее арифметическое, m - стандартная ошибка среднего, V - коэффициент вариации

На участке р. Брекса ниже зоны сброса дренажных вод «Казцинка» видовое богатство донных сообществ

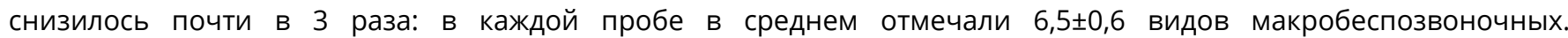
Коэффициенты внутригодовой (до 55\%) и межгодовой (9\%) вариации видового богатства макробеспозвоночных в целом соответствовали значениям, отмеченным для фонового участка реки, что связано со схожестью климатических условий и гидрологического режима сравниваемых участков реки и, так же, как и на вышележащем участке реки, обусловлено обеднением донных сообществ в периоды прохождения пика половодья и вылета имаго насекомых.

Для оценки возможности использования значений видового богатства макробеспозвоночных в определении уровня загрязнения реки были рассчитаны парные корреляции между числом видов в пробе и некоторыми абиотическими переменными исследованных участков. Число видов макробеспозвоночных (S) статистически значимо коррелировало с прозрачностью (d), содержанием взвешенных веществ (BB), концентрацией цинка (Zn) и меди (Сu) (табл.). При этом с увеличением прозрачности воды число видов в пробе возрастало, а с увеличением взвешенных веществ, цинка и меди - снижалось. Уменьшение видового богатства макробеспозвоночных при росте количества взвешенных веществ может быть связано как со снижением доли фильтраторов в донных сообществах, эффективность работы фильтрационных аппаратов которых снижается при попадании на них большого количества твердых частиц, так и с токсичным воздействием соединений тяжелых металлов (Сu и Zn), частично переносимых на взвеси и концентрация которых положительно коррелирует с содержанием взвешенных веществ в воде. Видовое богатство не зависело от факторов, колебания которых не выходили пределы, характерные для ненарушенных водотоков этой зоны: цветности (C), температуры (T), рН, содержания железа и карбонатов (табл. 2).

Таблица 2. Значения коэффициентов корреляции Спирмена между видовым богатством и некоторыми абиотическими переменными

\begin{tabular}{|c|c|c|c|c|c|c|c|c|c|c|}
\hline & $d$ & $C$ & $T$ & BB & $\mathrm{pH}$ & $\mathrm{Fe}$ & $\mathrm{Cu}$ & $\mathrm{Zn}$ & $\mathrm{CO}_{3}$ & $S$ \\
\hline$d$ & 1,00 & & & & & & & & & \\
\hline C & $-0,66$ & 1,00 & & & & & & & & \\
\hline $\mathrm{T}$ & 0,56 & $-0,37$ & 1,00 & & & & & & & \\
\hline BB & $-0,72$ & 0,58 & $-0,24$ & 1,00 & & & & & & \\
\hline $\mathrm{pH}$ & 0,53 & $-0,62$ & 0,38 & $-0,46$ & 1,00 & & & & & \\
\hline $\mathrm{Fe}$ & $-0,69$ & 0,84 & $-0,43$ & 0,55 & $-0,67$ & 1,00 & & & & \\
\hline $\mathrm{Cu}$ & $-0,51$ & 0,32 & $-0,14$ & 0,53 & $-0,21$ & 0,30 & 1,00 & & & \\
\hline $\mathrm{Zn}$ & $-0,23$ & 0,02 & $-0,08$ & 0,40 & $-0,19$ & $-0,05$ & 0,70 & 1,00 & & \\
\hline $\mathrm{CO}_{3}$ & 0,38 & $-0,67$ & 0,24 & $-0,54$ & 0,60 & $-0,70$ & $-0,18$ & $-0,05$ & 1,00 & \\
\hline$S$ & 0,39 & $-0,08$ & 0,13 & $-0,32$ & $-0,01$ & $-0,02$ & $-0,69$ & $-0,69$ & 0,11 & 1,00 \\
\hline
\end{tabular}

При горнодобывающей деятельности медь и цинк являются наиболее распространенными факторами загрязнения водоемов тяжелыми металлами, вызывая структурные изменения водных экосистем, в том числе и трансформацию их донных сообществ. Наиболее значимыми эффектами тяжелых металлов для сообществ 
Yanygina, L.V., Yevseyeva, A.A. Impact of mining on macroinvertebrate species.... Acta Biologica Sibirica, 2018, 4(3), 69-74

макробеспозвоночных являются: снижение видового богатства и разнообразия, уменьшение доли наиболее чувствительных групп макробеспозвоночных (веснянок, поденок, ручейников), замедление роста и продуктивности донных сообществ (Maret et al., 2003; Morgen, Trumble, 2010; Qu et al., 2010). Видовое богатство имеет некоторые преимущества перед другими биоиндикационными показателями, связанные с его универсальностью, независимостью от наличия индикаторных таксонов. При этом снижение видового богатства макробеспозвоночных при загрязнении водоемов тяжелыми металлами не зависит от типа водного объекта и отмечается не только на территории Казахстана, но и в водных объектах всего мира: водотоках Китая (Qu et al., 2010), Чили (Alvial, 2012), США (Maret et al., 2003), Японии (Iwasaki et al., 2009), Боливии (Smolders et al., 2003), Великобритании (Stockdale et al., 2009). Различные металлы и их сочетания оказывают схожий негативный эффект на видовое богатство (Morgen, Trumble, 2010; Malaj et al., 2012), что делает этот показатель перспективным в оценке экологического состояния водотоков наряду с другими биотическими индексами. Однако существенные вариации видового богатства рек, различающихся по их положению в речной системе, размеру, гидрологическим и другим естественным факторам формирования цоозенозов, затрудняют определение класса качества воды и требуют разработки региональных шкал качества по этому параметру, а также использования большого объема данных для определения фоновых значений видового богатства для рек разного типа.

Для большинства широкораспространенных в бассейне р. Брекса видов отсутствуют данные по их чувствительности к загрязнению. Поэтому особый интерес представляет анализ тенденций изменения частоты встречаемости отдельных видов на фоновых участках р. Брекса и в импактной зоне, что дает возможность выявления наиболее чувствительных и устойчивых к загрязнению видов макробеспозвоночных. Основу донных сообществ беспозвоночных на фоновом створе реки составляли личинки амфибиотических насекомых: ручейников, веснянок, поденок, суммарная доля которых в пробах достигала 90 \%. Следует отметить, что значительную долю видового богатства макробеспозвоночных реки составляют случайные виды. Снижение общего числа видов в импактной зоне произошло преимущественно за счет этих видов. Кроме того, в импактной зоне отмечены изменения состава константных видов по сравнению с фоновым участком. По частоте встречаемости на фоновом створе доминировали веснянки Skwala pusilla, поденки Epeorus pellucidus, Neoleptophlebia chocolata, ручейники Ceratopsyche newae, Brachycentrus americanus, Dicosmoecus palatus, Glossosoma altaicum, а также ракообразные Gammarus korbuensis, жесткокрылые Normandia nitens и личинки хирономид. Большинство этих видов статистически значимо $(p<0,05)$ снизили частоту встречаемости в импактной зоне по сравнению с фоновым участком (табл. 3), что позволяет отнести их к чувствительным к загрязнению видам. Исключение составили только личинки веснянок Skwala pusilla, жесткокрылых Normandia nitens и хирономид, частота встречаемости которых на фоновых участках и в импактной зоне статистически значимо не различалась $(p>0,05)$, что позволяет отнести их к устойчивым к загрязнению видам.

Таблица 3. Частота встречаемости макробеспозвоночных р. Брекса на фоновом участке (Б1) и в импактной зоне (Б2)

\begin{tabular}{|c|c|c|c|c|c|c|c|c|c|}
\hline \multirow[t]{2}{*}{ Таксон } & \multicolumn{4}{|l|}{ Б1 } & \multicolumn{4}{|l|}{52} & \multirow[t]{2}{*}{$-p^{*}$} \\
\hline & 2006 & 2007 & 2008 & 2009 & 2006 & 2007 & 2008 & 2009 & \\
\hline Ceratopsyche newae (Kolenati) & 71,4 & 71,4 & 42,9 & 71,4 & 0 & 28,6 & 28,6 & 14,3 & 0,03 \\
\hline Brachycentrus subnubilis (Curtis) & 57,1 & 57,1 & 85,7 & 57,1 & 42,9 & 42,9 & 42,9 & 14,3 & 0,02 \\
\hline Chironomidae & 71,4 & 71,4 & 85,7 & 85,7 & 71,4 & 85,7 & 85,7 & 85,7 & 0,60 \\
\hline Epeorus pellucidus Brodsky & 71,4 & 85,7 & 85,7 & 71,4 & 14,3 & 14,3 & 14,3 & 28,6 & 0,02 \\
\hline Gammarus korbuensis (Martynov) & 85,7 & 85,7 & 100 & 100 & 0 & 14,3 & 28,6 & 0 & 0,03 \\
\hline Skwala pusilla Klapalek & 57,1 & 42,9 & 57,1 & 28,6 & 28,6 & 42,9 & 42,9 & 28,6 & 0,28 \\
\hline Neoleptophlebia chocolata Imanishi & 42,9 & 42,9 & 71,4 & 71,4 & 0 & 0 & 0 & 28,6 & 0,02 \\
\hline Normandia nitens (Muller) & 28,6 & 57,1 & 71,4 & 100 & 28,6 & 28,6 & 0 & 42,9 & 0,10 \\
\hline Glossosoma altaica Mart. & 28,6 & 42,9 & 42,9 & 28,6 & 0 & 0 & 14,3 & 14,3 & 0,03 \\
\hline Dicosmoecus palatus McLachlan & 57,1 & 42,9 & 71,4 & 42,9 & 0 & 14,3 & 0 & 0 & 0,02 \\
\hline
\end{tabular}

Примечание: ${ }^{*}$ - уровень статистической значимости различий между створами

\section{Заключение}

Дренажные воды предприятий горнодобывающего комплекса, попадающие в р. Брекса, негативно воздействуют на донные сообщества реки. В импактной зоне реки отмечено снижение видового богатства макробеспозвоночных, наблюдались перестройки состава комплекса наиболее часто встречающихся видов. В результате проведенного исследования выявлена высокая чувствительность к загрязнению тяжелыми металлами палеарктических видов поденок Epeorus pellucidus, Neoleptophlebia chocolata и ручейников Brachycentrus americanus, 
Yanygina, L.V., Yevseyeva, A.A. Impact of mining on macroinvertebrate species.... Acta Biologica Sibirica, 2018, 4(3), 69-74

Glossosoma altaicum. Результаты данной работы показывают необходимость проведения дальнейших исследований особенностей перестроек разнотипных донных сообществ при различных видах антропогенной нагрузки и последующей разработки региональных модификаций биологических показателей качества среды.

\section{References}

Alvial, I.E., Tapia, D.H., Castro, M.J., Duran, B.C., Verdugo, C.A. (2012). Analysis of benthic macroinvertebrates and biotic indices to evaluate water quality in rivers impacted by mining activities in northern Chile. Knowledge and Management of Aquatic Ecosystems, 407, doi: 10.1051/kmae/2012027.

Bakanov, A.I. (2005). Kolichestvennaya ocenka dominirovaniya v ehkologicheskih soobshchestvah [The quantitative assessment of dominance in ecological communities]. Kolichestvennye metody ehkologii i gidrobiologii. Tol'yatti. pp. 37-67 (in Russian).

Bioraznoobrazie i dinamika ehkosistem: informacionnye tekhnologii i modelirovanie (2006) [Biodiversity and dynamics of ecosystems: Information technologies and modeling]. SB RAS, Novosibirsk (in Russian).

Iwasaki, Y., Kagaya, T., Miyamoto, K.I., Matsuda, H. (2009) Effects of heavy metals on riverine benthic macroinvertebrate assemblages with reference to potential food availability for drift-feeding fishes. Environ Toxicol Chem, 28, 354-363, doi:10.1897/08-200.1

Malaj, E., Grote, M., Schäfer, R.B., Brack, W., Carsten von der Ohe, P. (2012). Physiological sensitivity of freshwater macroinvertebrates to heavy metals. Environ Toxicol Chem, 31(8), 1754-1764, doi: 10.1002/etc.1868.

Maret, T.R., Cain, D.J., MacCoy, D.E. and Short, T.M. (2003). Response of benthic invertebrate assemblages to metal exposure and bioaccumulation associated with hard-rock mining in northwestern streams USA. J. N. Am. Benthol. Soc., 22, 598-620.

Morgen, C., Trumble, J. (2010). The impact of metals and metalloids on insect behaviour. Entomologia Experimentalis et Applicata, 135, 1-17.

Qu, X., Wu, N., Tang, T., Ca, Q. and Park, Y-S. (2010). Effects of heavy metals on benthic macroinvertebrate communities in high mountain streams. Ann. Limnol. - Int. J. Lim., 46, 291-302, doi: 10.1051/limn/2010027.

Smolders, A., Lock, R., Van der Velde, G. et al. (2003) Effects of Mining Activities on Heavy Metal Concentrations in Water, Sediment, and Macroinvertebrates in Different Reaches of the Pilcomayo River, South America. Arch. Environ. Contam. Toxicol., 44, 0314. doi: 10.1007/s00244-002-2042-1.

Stockdale, A., Tipping, E., Lofts, S., Ormerod, S.J., Clements, W.H., Blust, R. (2010) Toxicity of proton-metal mixtures in the field: linking stream macroinvertebrate species diversity to chemical speciation and bioavailability. Aquat Toxicol, 100, 112-119. doi:10.1016/j.aquat ox.2010.07.018.

Tishkov, A.A. (2006). Sohranenie biologicheskogo raznoobraziya v Rossii [Conservation of biological diversity in Russia]. Rossiya v okruzhayushchem mire, Moscow. pp. 82-124 (in Russian)

Yanygina, L.V. (2017) Macrozoobenthos as an indicator of the ecological state of mountain watercourses. Russian Journal of Ecology, 2017, 48(2), 185-190.

\section{Citation:}

Yanygina, L.V., Yevseyeva, A.A. (2018). Impact of mining on macroinvertebrate species richness in mountain streams. Acta Biologica Sibirica, 4 (3), 69-74.

Submitted: 18.05.2018. Accepted: 05.07.2018

cross ref http://dx.doi.org/10.14258/abs.v4i3.4372

(C) 2018 by the authors. Submitted for possible open access publication under the terms and conditions of the Creative Commons Attribution (CC BY) license (http://creativecommons.org/licenses/by/4.0/). 